Check for updates

Cite this: Metallomics, 2017, 9, 1470

Received 5th May 2017,

Accepted 27th June 2017

DOI: $10.1039 / \mathrm{c} 7 \mathrm{mt} 00146 \mathrm{k}$

rsc.li/metallomics

\section{Recent structural insights into the function of copper nitrite reductases}

\author{
Sam Horrell, Demet Kekilli, Richard W. Strange (D) and Michael A. Hough (D)* \\ Copper nitrite reductases (CuNiR) carry out the first committed step of the denitrification pathway of the \\ global nitrogen cycle, the reduction of nitrite $\left(\mathrm{NO}_{2}^{-}\right)$to nitric oxide (NO). As such, they are of major \\ agronomic and environmental importance. CuNiRs occur primarily in denitrifying soil bacteria which \\ carry out the overall reduction of nitrate to dinitrogen. In this article, we review the insights gained into \\ copper nitrite reductase (CuNiR) function from three dimensional structures. We particularly focus on \\ developments over the last decade, including insights from serial femtosecond crystallography using \\ X-ray free electron lasers (XFELS) and from the recently discovered 3-domain CuNiRs.
}

\section{Introduction}

Copper nitrite reductases (CuNiRs) are key enzymes in the nitrogen cycle, occurring in a wide range of denitrifying bacteria and fungi. ${ }^{1}$ The denitrification pathway in these organisms couples ATP synthesis with the reduction of nitrate $\left(\mathrm{NO}_{3}{ }^{-}\right)$or nitrite $\left(\mathrm{NO}_{2}{ }^{-}\right)$to dinitrogen $\left(\mathrm{N}_{2}\right)$, via nitric oxide (NO) and nitrous oxide $\left(\mathrm{N}_{2} \mathrm{O}\right)$ intermediates. ${ }^{2,3}$ This pathway is critical in the return of fixed nitrogen to the atmosphere and in controlling the level of biologically available nitrogen in the soil. The extensive use of nitrogen containing fertilisers from the Haber-Bosch process can cause major environmental problems if the denitrification pathway becomes overloaded. ${ }^{2}$ Moreover, the $\mathrm{N}_{2} \mathrm{O}$ intermediate in the denitrification pathway is a potent greenhouse gas. ${ }^{4}$ The roles of different metalloenzymes in denitrification and their environmental and agricultural impacts have been recently reviewed. ${ }^{5}$

The first committed step (i.e. the first effectively irreversible reaction in the pathway that commits the organism to generate the final product) in denitrification is the reduction of nitrite to NO (eqn (1)) and this is carried out either by Fe-containing cytochrome $c d 1$ nitrite reductases, penta- or octa-haem nitrite reductases or by CuNiRs, encoded by the nirk gene.

$$
\mathrm{NO}_{2}{ }^{-}+\mathrm{e}^{-}+2 \mathrm{H}^{+} \rightarrow \mathrm{NO}+\mathrm{H}_{2} \mathrm{O}
$$

Many detailed biochemical, spectroscopic, kinetic and structural studies have investigated the catalytic mechanisms of the CuNiRs and we describe only the key points in this review, focusing on structural insights. We describe the three-dimensional structures of CuNiRs and how these have led to profound insights into enzyme function and catalytic mechanism. We particularly focus

School of Biological Sciences, University of Essex, Wivenhoe Park, Colchester, CO4 3SQ, UK. E-mail: mahough@essex.ac.uk; Tel: +44 1206873317 on developments in the last decade including the discovery of extended CuNiRs, the application of serial femtosecond crystallography (SFX) and approaches to characterise the enzyme mechanism within protein crystals.

\section{Overall fold and oligomeric state of CuNiRs}

The majority of CuNiRs are trimeric, with each $\sim 37 \mathrm{kDa}$ monomer comprising two cupredoxin ( $\beta$-sandwich) domains, Fig. $1 \mathrm{~A}$ and B. ${ }^{6}$ Each of these domains has a similar architecture to that of monomeric cupredoxin proteins, such as azurin, pseudoazurin and rusticyanin, that act as electron donor partner proteins to CuNiRs. ${ }^{7}$ The C-terminal region of each cupredoxinlike monomer forms an extended loop that wraps around an adjacent monomer contributing to the stability of the trimer. ${ }^{6}$

These well-characterised two-domain CuNiRs are assigned as classes I and II, depending on the colour arising from their type $1 \mathrm{Cu}(\mathrm{T} 1 \mathrm{Cu})$ centre, with class I being blue and class II being green. Class III has an additional T1Cu domain with a hexameric oligomer and is greenish-blue due to the presence of two $\mathrm{Cu}$ centres, one each of class I and II. ${ }^{8}$ This class III CuNiR is an example of a recently discovered group of extended (threedomain) CuNiRs, ${ }^{9}$ that exist with additional fused $\mathrm{N}$ - or C-terminal domains containing a $\mathrm{T} 1 \mathrm{Cu}$ or cytochrome haem redox centre, respectively (Fig. 1). ${ }^{10}$ Regardless of such variations, the core structure of $\mathrm{T} 1 \mathrm{Cu}$ and type $2 \mathrm{Cu}(\mathrm{T} 2 \mathrm{Cu})$ sites in the trimeric core is largely conserved. We will first discuss the structure and function of the trimeric CuNiRs before highlighting variations in the more recently characterised extended CuNiRs.

\section{The copper centres of CuNiRs in the resting state}

All CuNiRs characterised to date contain an electron-providing $\mathrm{T} 1 \mathrm{Cu}$ centre and a catalytic $\mathrm{T} 2 \mathrm{Cu}$ centre. At the $\mathrm{T} 1 \mathrm{Cu}$ site, the $\mathrm{Cu}$ is coordinated by two His, one Cys and an axial Met forming a tetrahedral geometry, Fig. $2 .{ }^{6}$ The structural changes within 
A

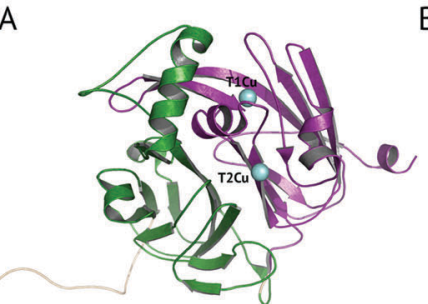

C

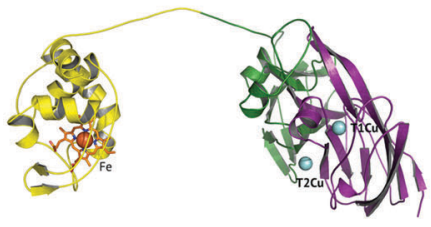

D

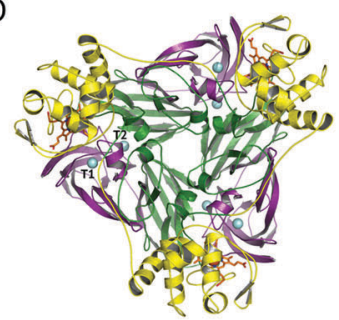

$\mathrm{F}$
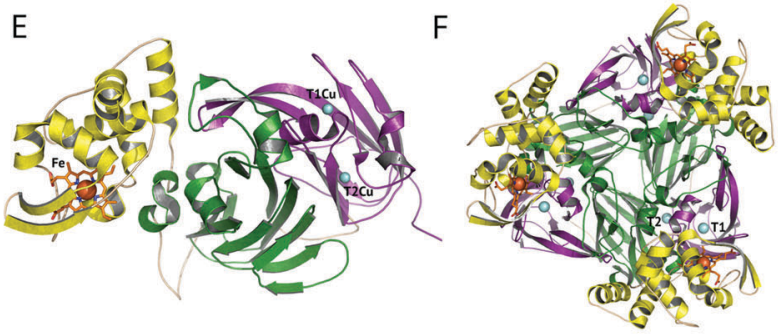

G

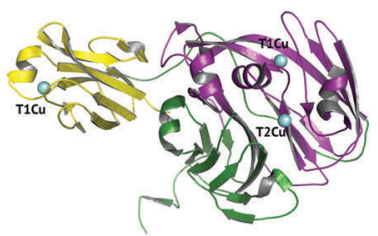

$\mathrm{H}$

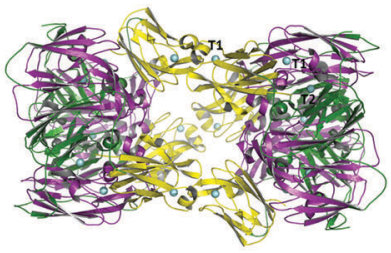

Fig. 1 The domain and oligomeric structures of CuNiRs. In class I and II proteins, two cupredoxin domains are present per monomer, here coloured green and purple. Class III CuNiRs have an additional C- or $\mathrm{N}$-terminal domain (yellow) containing $\mathrm{T} 1 \mathrm{Cu}$ or haem. The two-domain proteins form a trimeric oligomer, shown in panels $\mathrm{A}$ and $\mathrm{B}$. In the threedomain proteins from $P h N i R$ and RpNiR the additional C-terminal cytochrome domain, panels $C$ and $E$, forms trimeric oligomers, panels $D$ and $F$, respectively. In the three-domain $\mathrm{HdNiR}$ an additional T1Cu N-terminal domain is present, panel $G$, and the biological unit appears to be a hexameric oligomer, panel $\mathrm{H}$.

$\mathrm{T} 1 \mathrm{Cu}$ sites between the $\mathrm{Cu}$ (II) and $\mathrm{Cu}(\mathrm{I})$ states are small (consistent with an entactic/rack state), and close to the level of precision at the typical resolutions of crystal structures.

Atomic resolution structures provide more accuracy for bond length parameters but usually at the expense of higher $\mathrm{X}$-ray dose which can readily reduce the $\mathrm{T} 1 \mathrm{Cu}$ to the $\mathrm{Cu}(\mathrm{I})$ state. EXAFS studies suggest an increase in the $\mathrm{Cu}-\mathrm{Cys}$ bond length on reduction of the blue copper protein azurin of some $0.07 \AA{ }^{11}$

As the main chromophore of $\mathrm{CuNiR}$, the $\mathrm{T} 1 \mathrm{Cu}$ site is responsible for the colour of the protein in the cupric state. In general, $\mathrm{T} 1 \mathrm{Cu}$ sites in copper proteins can vary widely in colour, including blue, green, red and purple. ${ }^{12,13}$ The relationship

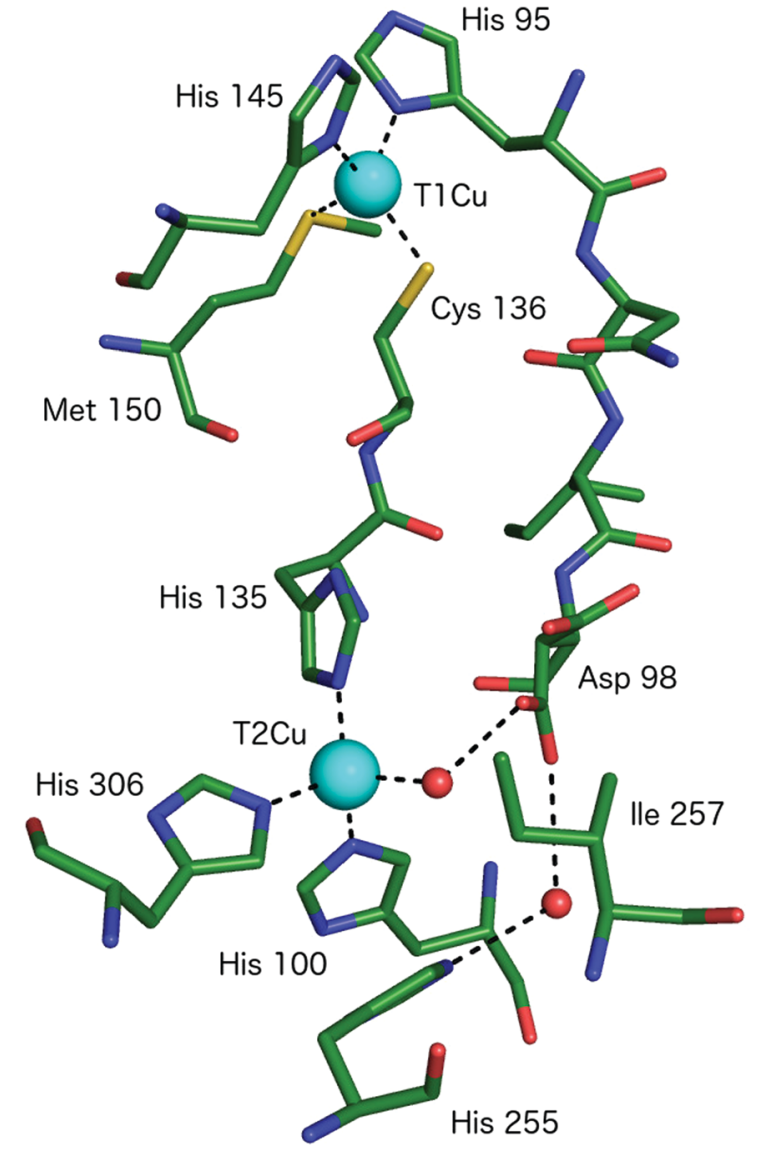

Fig. 2 The $\mathrm{T} 1 \mathrm{Cu}$ and $\mathrm{T} 2 \mathrm{Cu}$ centres of $\mathrm{AcNiR}$ and the protein links between them. The T1Cu atom has ( $\mathrm{His})_{2} \mathrm{CysMet}$ ligation and is linked to the catalytic $\mathrm{T} 2 \mathrm{Cu}$ centre by a Cys-His bridge. A second link is made between the $\mathrm{T} 1 \mathrm{Cu}$ ligand His95 and $\mathrm{T} 2 \mathrm{Cu}$ site residue Asp98, proposed to be a sensor loop, enabling intramolecular T1-T2 electron transfer. The T2Cu coordination is completed by three more His residues, one of which originates from an adjacent monomer of the trimer and a water molecule. Image generated from the structure of resting state $A c N i R$ at $0.9 \AA$ resolution (PDB 2BW4). ${ }^{17}$

between $\mathrm{T} 1 \mathrm{Cu}$ colour and geometry has been systematically studied. CuNiRs from different species appear blue, green or 'bluish-green' despite possessing an identical set of ligand residues. Insights into the relationship between $\mathrm{T} 1 \mathrm{Cu}$ structure, colour and redox potential have been obtained by comparison of structures of blue and green CuNiRs and by mutagenesis of first and second coordination shell residues. Blue CuNiRs typically exhibit a long/weak Cu-Met bond $\sim 2.9$ A while in green CuNiRs this bond is much shorter.

Work from Solomon and co-workers revealed that in green CuNiRs, two spectral forms were present, with the ratio between these being strongly temperature dependent. ${ }^{14}$ At low temperatures, a green form with a strong Met-Cu interaction is dominant, while at higher temperatures, a blue form becomes more populated, with a weaker $\mathrm{Cu}-\mathrm{Met}$ interaction. The $\mathrm{T} 1 \mathrm{Cu}$ geometry, colour and redox potential are profoundly affected by mutation of ligand residues with consequent effects on enzyme activity.

The catalytic T2Cu is separated from the T1Cu by $\sim 12.6 \AA$ and the centres are connected by a Cys-His bridge (for rapid 

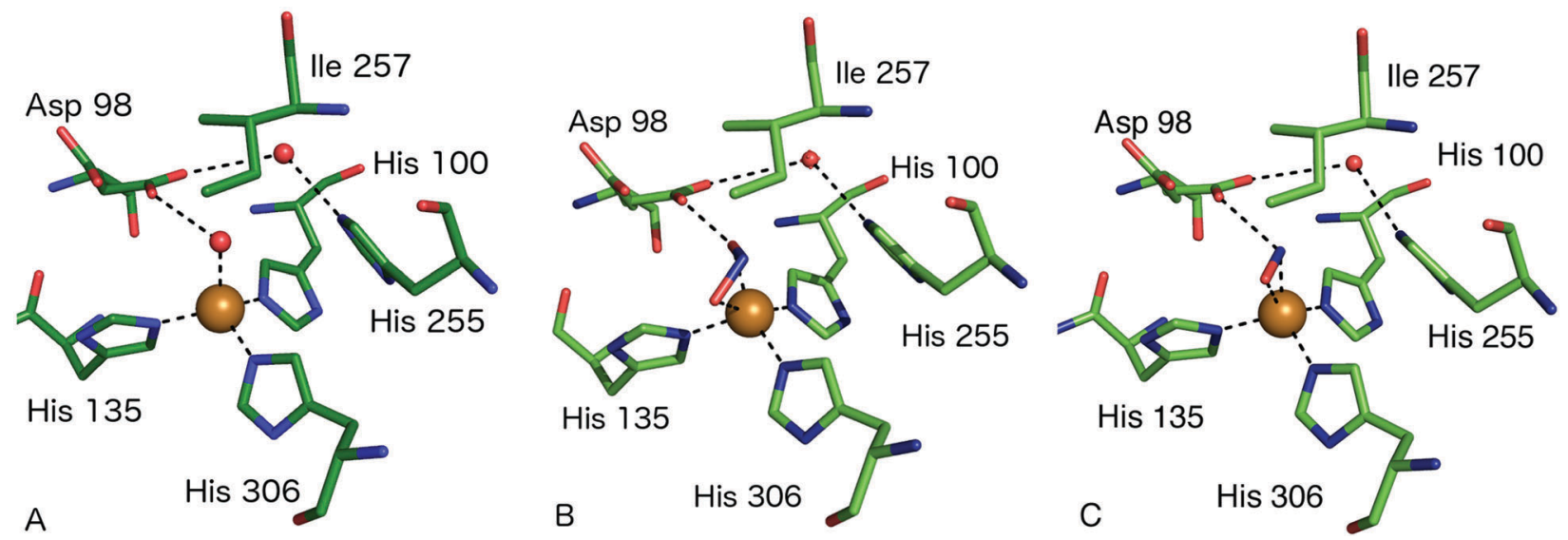

Fig. 3 Type $2 \mathrm{Cu}$ site structures (A) resting state $\mathrm{AcNiR}$ with a water molecule bound to the T2Cu (PDB 2BW4); (B) nitrite bound to the T2Cu site in a side-on bidentate O manner (PDB 5AKR); (C) the T2Cu site of AcNiR bound to NO at $1.22 \AA$ resolution (PDB 5I6N). The NO ligand is bound in a side-on manner with near-equidistant $\mathrm{Cu}-\mathrm{N}$ and $\mathrm{Cu}-\mathrm{O}$ bonds. Residue Asp98 forms a $\mathrm{H}$-bond to the $\mathrm{N}$ atom of $\mathrm{NO}$ and is oriented toward the proton delivery channel. Panels $A$ and $B$ are from the structures described in ref. 18 while panel $C$ is from ref. 55.

electron transfer) comprised of the $\mathrm{T} 1 \mathrm{Cu}$ ligand Cys and a $\mathrm{T} 2 \mathrm{Cu}$ ligating His. ${ }^{6}$ The $\mathrm{T} 2 \mathrm{Cu}$ has $(\mathrm{His})_{3}-\mathrm{H}_{2} \mathrm{O}$ ligation in the resting state with a tetrahedral geometry, Fig. 2 and $3 \mathrm{~A}$. One of the three His ligands is provided from an adjacent monomer of the $\mathrm{CuNiR}$ trimer. Upon reduction (in the absence of substrate), the $\mathrm{T} 2 \mathrm{Cu}$ loses the coordinated $\mathrm{H}_{2} \mathrm{O}$ resulting in $\mathrm{Cu}-(\mathrm{His})_{3}$ ligation. ${ }^{15}$ The $\mathrm{T} 2 \mathrm{Cu}$ centre possesses only a weak UV-visible absorption spectrum that is obscured by the much stronger absorbance of the $\mathrm{T} 1 \mathrm{Cu}$ centre. ${ }^{16}$ The $\mathrm{T} 2 \mathrm{Cu}$ ligand binding pocket contains several conserved residues with proposed functional roles related to substrate access, specificity, activity, electron transfer \& proton transfer. ${ }^{16}$ The $\mathrm{Cu}$-coordinated water molecule is H-bonded to an aspartic acid residue (Asp $\mathrm{AAT}_{\mathrm{CAT}}$ and, via a water bridge, to a conserved His $\left(\mathrm{His}_{\mathrm{CAT}}\right) .{ }^{6}$ Asp $\mathrm{PAT}_{\mathrm{CAT}}$ has been proposed to play roles in substrate guidance/stabilisation and to act as a proton donor, ${ }^{17}$ while His $_{\mathrm{CAT}}$ acts as a second proton donor. Crystal structures show that Asp CAT $_{\text {can }}$ cadopt two different conformations, named 'gatekeeper' - pointed away from $\mathrm{T} 2 \mathrm{Cu}$ and 'proximal' - oriented towards $\mathrm{T} 2 \mathrm{Cu}$ and $\mathrm{H}$-bonding to the bound water molecule in the resting state. ${ }^{18}$ Mutation of Asp $\mathrm{AAT}_{\mathrm{CAT}}$ to asparagine (Asn) in AxNiR eliminated catalytic activity providing strong evidence for its role in proton transfer. ${ }^{19}$ The properties of Asp ${ }_{\mathrm{CAT}}$ and $\mathrm{His}_{\mathrm{CAT}}$ may provide the rationale for the observed $\mathrm{pH}$ dependence of CuNiR activity. Solomon and coworkers have reported a $\mathrm{p} K_{\mathrm{a}}$ of 6.4 for Asp $\mathrm{AsAT}_{\mathrm{C}}$ (in $\mathrm{AxNiR}$ ) when $\mathrm{NO}_{2}{ }^{-}$is bound. ${ }^{20}$ Finally, an isoleucine (Ile $\mathrm{CAT}$ ) residue that lies above the T2Cu binding site has been shown by structural studies ${ }^{21}$ to profoundly influence substrate orientation and consequently the catalytic activity.

\section{Enzymatic mechanism of nitrite reduction: structural insights}

The consensus mechanism for two domain CuNiRs begins with the resting state enzyme, with a water bound to the T2Cu centre, Fig. 3A. On the basis of X-ray crystallography and EXAFS studies on native and site-selected $A x N i R$ mutants, supported by kinetics measurements, a catalytic mechanism was initially proposed in which $\mathrm{NO}_{2}{ }^{-}$coordinates to the $\mathrm{T} 2 \mathrm{Cu}(\mathrm{II})$, displacing the water molecule in the native enzyme, Fig. 3B. In the absence of nitrite at the $\mathrm{T} 2 \mathrm{Cu}$ there is a limited potential for electron transfer (ET) from the $\mathrm{T} 1 \mathrm{Cu}$, but following nitrite binding ET from $\mathrm{T} 1 \mathrm{Cu}(\mathrm{I})$ to the $\mathrm{T} 2 \mathrm{Cu}$ site occurs, ${ }^{15,22,23}$ which reduces the $\mathrm{T} 2 \mathrm{Cu}$. Two protons required for the catalytic reaction are thought to be provided by residues His254 ( $\left.\mathrm{His}_{\mathrm{CAT}}\right)$ and Asp97 (Asp ${ }_{\mathrm{CAT}}$ ) and the proton-coupled electron-transfer (PCET) from $\mathrm{T} 1 \mathrm{Cu}$ to $\mathrm{T} 2 \mathrm{Cu}$, involving the $\mathrm{His}_{\mathrm{CAT}}$ and $\mathrm{Asp}_{\mathrm{CAT}}$ residues, is thought to be the rate-determining step. ${ }^{24,25}$ In this PCET process, the two protons are provided to the bound $\mathrm{NO}_{2}{ }^{-}$along with an ET from the reduced $\mathrm{T} 2 \mathrm{Cu}$, to yield the NO product, Fig. 3C. This product then dissociates from the $\mathrm{T} 2 \mathrm{Cu}$, allowing water to rebind to reform the oxidised resting $\mathrm{T} 2 \mathrm{Cu}$ state, Fig. 3A. Structural and kinetic studies on a number of other CuNiRs gave apparently conflicting evidence on whether the intramolecular ET occurred before or after $\mathrm{NO}_{2}{ }^{-}$binding $[$e.g. ref. 15, 26 and 27]. These conflicts have been mostly reconciled by a kinetic scheme for catalytic turnover in which two alternative mechanistic pathways are possible, varying in the sequence of ET and binding of nitrite, depending on the $\mathrm{pH}$ and nitrite concentration. ${ }^{28}$ The catalytic mechanism at the $\mathrm{T} 2 \mathrm{Cu}$ site of CuNiRs has also been extensively explored using theoretical methods based on the crystal structures, though as yet no clear consensus has been reached on the precise nature and order of the proposed PCET reaction. ${ }^{29-34}$

Key features relevant to this mechanism that are informed by structures include the modes of substrate and product binding, the likely electron and proton transfer pathways and steps and the conserved water structure within the active site pocket.

\section{Substrate binding to the T2Cu centre and specificity}

The first structure of a nitrite-bound CuNiR complex adduct was determined in $1991 .^{6}$ Since then, structures have been determined of $\mathrm{NO}_{2}{ }^{-}$and NO-bound complexes at a variety of resolutions and $\mathrm{pH}$ of native and mutant $\mathrm{CuNiRs}$ from different organisms. ${ }^{18,19,21-23,27,35-56}$ Nitrite has typically been observed 
to bind either in an asymmetric bidentate binding geometry with its $\mathrm{O} 1$ and $\mathrm{O} 2$ atoms ligating to $\mathrm{T} 2 \mathrm{Cu}(\mathrm{II})$ or in a 'side-on' geometry with similar distances from $\mathrm{T} 2 \mathrm{Cu}$ to the three atoms of nitrite. One of the highest resolution structures of a CuNiRnitrite complex is that of $A c \mathrm{NiR}$, to $1.10 \AA$ resolution, ${ }^{18}$ where nitrite was observed with bidentate binding to $\mathrm{T} 2 \mathrm{Cu}$ and dual conformations of Asp98 $8_{\text {CAT }}$ were present, with the proposal that the gatekeeper conformation of Asp98 (Asp CAT $_{\text {C }}$ may be important for guiding $\mathrm{NO}_{2}{ }^{-}$to its binding site at the $\mathrm{T} 2 \mathrm{Cu}$. The proximal conformation, on the contrary, is significant for proton transfer, bond-cleavage and formation and release of the product, NO. The resting state has water bound to oxidised $\mathrm{T} 2 \mathrm{Cu}$ and forms a $\mathrm{H}$-bond to the negatively charged Asp $\mathrm{CAT}_{\mathrm{CAT}}$ residue. Nitrite is observed to bind to the $\mathrm{T} 2 \mathrm{Cu}$ ion via a O-coordinate bidentate mode, displacing the bound water molecule and forming $\mathrm{H}$-bonds between the $\mathrm{O}^{\delta 2}$ atom of $\mathrm{Asp}_{\mathrm{CAT}}$ and the $\mathrm{O} 2$ atom of nitrite. Proton transfer occurs from the $\mathrm{Asp}_{\mathrm{CAT}}$ to the nitrite to form the intermediate $\mathrm{T} 2 \mathrm{Cu}^{+} \mathrm{NOOH}$ on reduction of the $\mathrm{T} 2 \mathrm{Cu}$ site. His255 ( His $_{\mathrm{CAT}}$ ) facilitates bond cleavage of the $\mathrm{N}-\mathrm{ON}$ bond to form the product, NO, by supplying the second proton in the widely-accepted mechanism. The NO product dissociates and leaves the resting water-bound oxidised $\mathrm{T} 2 \mathrm{Cu}$ ion. Structures have been determined of ascorbate-reduced and reduced nitritesoaked $A f \mathrm{NiR}$ at 2.0 [PDB 1AQ8] and $1.85 \AA$ [PDB 1AS8] resolutions, respectively, with nitrite bound to reduced $\mathrm{T} 2 \mathrm{Cu}$, revealing few structural changes relative to the oxidised form. ${ }^{41}$

In the different structures of nitrite complexes, bidentate nitrite has been modelled in both 'top-hat' and 'side-on' positions. XFEL SFX ${ }^{54}$ data have revealed that the 'top-hat' mode is the binding geometry initially present in the $\mathrm{T} 2 \mathrm{Cu}$ (II) form of the enzyme and that the side-on may be the result of $\mathrm{T} 2 \mathrm{Cu}$ reduction. This highlights that great care must be taken in crystallographic studies of nitrite-bound CuNiRs due to the propensity for X-ray generated photoelectrons to initiate catalysis within the crystal, leading to the conversion of substrate to $\mathrm{NO}$ at the $\mathrm{T} 2 \mathrm{Cu}$ site. Structures determined from CuNiR nitrite complexes using high $\mathrm{X}$-ray doses in many cases reveal a significant population of the T2Cu-NO product. ${ }^{27}$ Most recently this phenomenon has been exploited to drive in crystallo reactions to generate 'structural movies' of enzyme catalysis in green $A c \mathrm{NiR}^{55,57}$ and thermostable Geobacillus thermodenitrificans (GtNiR). ${ }^{58}$

T2Cu site mutations in AfNiR significantly altered the binding mode of nitrite ${ }^{21}$ and these were related to changes in enzyme activity. Mutation of this Ile $_{\mathrm{CAT}}$ to Val or Leu led to asymmetric bidentate $\mathrm{NO}_{2}{ }^{-}$binding while mutation to Met, Thr, Gly or Ala resulted in monodentate coordination, allowing a water molecule to also bind to $\mathrm{T} 2 \mathrm{Cu}$ in a position close to that usually occupied by the $\mathrm{O} 2$ atom of nitrite. Monodentate nitrite binding was associated with greatly reduced catalytic activity, pointing to a key role for Ile $_{\mathrm{CAT}}$ in promoting a nitrite binding geometry conducive during catalysis. Crystal structures were determined

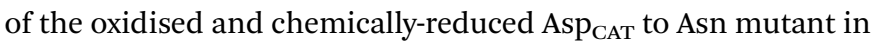
Af $\mathrm{NiR}^{35}$ In these structures, nitrite was bound in a side-on manner with an increased level of disorder, ascribed to a shift of Asn relative to Asp producing an unfavourable geometry for $\mathrm{H}$-bonding with the bound protonated nitrite. However, this
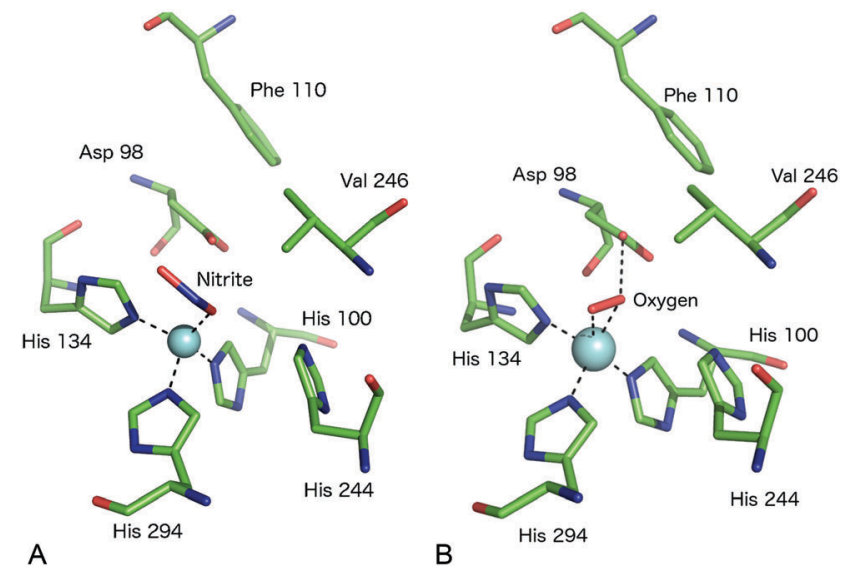

Fig. 4 The T2Cu site environment of GtNiR. (A) The nitrite-complex (PDB code 3 WKP), ${ }^{52}$ note the monodentate binding of nitrite via a single $O$ atom, the substitution of $\| e_{C A T}$ with a Val residue and the steric restriction of the gatekeeper Asp CAT (Asp98) conformation (seen in other CuNiRs) by Phe110, resulting in only the proximal conformation being observed; (B) oxygen binding to GtNiR (PDB code $3 \mathrm{WNJ}) .{ }^{61}$ Note that partially occupied water molecules are omitted for clarity. $\mathrm{Cu}$ atoms are shown as cyan spheres.

disorder could simply represent a mixture of top-hat and side-on nitrite molecules within the crystal. The His CAT $_{\text {To Asn mutant of }}$ Af NiR showed no displacement of the water molecule and the nitrite is bound to the $\mathrm{T} 2 \mathrm{Cu}$ in a monodentate manner via an $\mathrm{O}$ atom. Nitrite is oriented away from Ile257 and towards an Ala residue and the pocket $\mathrm{H}$-bonding network is drastically altered in the $\mathrm{H} 255 \mathrm{~N}$ mutant, indicating an essential role for nitrite binding and function. ${ }^{35}$

A somewhat different binding mode for nitrite was observed in a structure of the C135A mutant (which eliminates $\mathrm{T} 1 \mathrm{Cu}$ binding) of the thermophile $G t \mathrm{NiR},{ }^{52}$ a close homologue of $G k \mathrm{NiR}$. The $1.90 \AA$ A structure showed nitrite bound in a monodentate manner via its $\mathrm{O} 2$ atom with this atom being positioned to form a $\mathrm{H}$-bond to Asp $\mathrm{AAT}_{\mathrm{CAT}}$. His CAT $_{\mathrm{C}}$ adopted a rotated conformation likely due to the formation of a $\mathrm{H}$-bond to a Gln residue rather than the

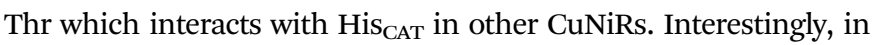
this enzyme, the gatekeeper conformation of Asp CAT $_{\text {and the }}$

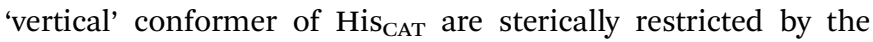
unusual position of a Phe residue near to the catalytic pocket which provides additional rigidity to the active site in this enzyme from a thermophile, Fig. 4A. Intriguingly, when the structure of the nitrite complex of $G t \mathrm{NiR}$ was determined at $320 \mathrm{~K}$, the observed substrate binding mode was side-on, similar to that observed in other CuNiRs, ${ }^{53}$ a result ascribed to increased dynamic flexibility of the pocket at the higher temperature.

\section{Substrate and copper access to the T2Cu site}

The T2Cu site, as mentioned previously, makes up the active substrate-binding site and is coordinated by three His and one $\mathrm{H}_{2} \mathrm{O} / \mathrm{OH}^{-}$ligand. ${ }^{38}$ In the resting state nitrite has access to the T2Cu centre via a channel some $\sim 12 \AA$ deep from the protein surface and displaces the $\mathrm{H}_{2} \mathrm{O}$ ligand to initiate catalysis. Intriguingly, mutation of the surface-exposed Phe306 to a Cys 
residue some $12 \AA$ away from $\mathrm{T} 2 \mathrm{Cu}$ in $A x \mathrm{NiR}$ resulted in a change to the second coordination sphere of the $\mathrm{Cu}$ with consequent effects on the rate-limiting step of the enzyme reaction. ${ }^{59}$ In this F306C mutant, the substrate access channel is more open and contains an additional water bound to the T2Cu-coordinating water molecule. The specific activity was remarkably increased four-fold while the apparent nitrite affinity and the rate of intramolecular ET were lower than in native AxNiR. In this mutant, intramolecular ET became the rate-limiting step.

\section{Binding of small molecule ligands to the T2Cu centre}

Native CuNiR can bind small molecules including acetate, nitrate, formate, azide and $\mathrm{N}_{2} \mathrm{O}$, of which complex structures have all been determined crystallographically. The binding mode of such ligands ${ }^{60}$ is strongly influenced by the pocket residues $\mathrm{Ile}_{\mathrm{CAT}}$ and $\mathrm{Asp}_{\mathrm{CAT}}$ and these, together with the dimensions of the substrate access channel, act to prevent the binding of larger ligands. Monoatomic species such as chloride have also been shown to bind to $\mathrm{T} 2 \mathrm{Cu} .{ }^{42,54}$

A recent study of $G t \mathrm{NiR}$ at $1.20 \AA$ resolution ${ }^{61}$ revealed electron density consistent with the interpretation that an oxygen ligand was bound at the $\mathrm{T} 2 \mathrm{Cu}$ site, in the absence of nitrite or NO, Fig. 4B. CuNiRs have the ability to catalyse the two-electron reduction of $\mathrm{O}_{2}$ to hydrogen peroxide $\left(\mathrm{H}_{2} \mathrm{O}_{2}\right)$ but no structural data for this molecular oxygen ligand has previously been observed. In the GtNiR structure, the $\mathrm{O}_{2}$ ligand was modelled in a side-on manner with one short (2.1 $)$ ) and one longer $(2.4 \AA) \mathrm{Cu}-\mathrm{O}$ bond length. Oxygen forms $\mathrm{H}$-bonds with Asp $_{\text {CAT }}$ and a water molecule and also makes van der Waals contacts with $\mathrm{Val}_{\mathrm{CAT}}$. This latter hydrophobic interaction appears to be related to the side on binding mode as previously proposed for NO binding. Oxygen binding has not been observed in other CuNiRs and was proposed to be observable in $G t \mathrm{NiR}$ due to the presence of a Val residue in place of $\mathrm{Ile}_{\mathrm{CAT}}$, which creates an unusually open substrate binding pocket and/or the slower $\mathrm{O}_{2}$-reduction rate in the CuNiR from this species. Interestingly, the structure of a CuNiR from Nitrosomonas europaea ${ }^{50}$ revealed a much more restricted substrate channel than in other CuNiRs, proposed to be the basis of the unusual $\mathrm{O}_{2}$ tolerance of this enzyme enabling it to function in an aerobic environment. In addition, a second water channel was observed and assigned as a water exit channel in this enzyme.

It is a notable feature of CuNiRs that they possess a significant superoxide dismutase activity, ${ }^{15,62}$ for example $A x \mathrm{NiR}$ at a remarkable $\sim 56 \%$ activity compared to bovine $\mathrm{Cu}, \mathrm{Zn}$ superoxide dismutase (CuZnSOD), one of the most efficient enzymes known. The structural similarity between the $\mathrm{Cu}(\mathrm{I})$ form of the T2Cu site and that of CuZnSOD has been noted from both EXAFS and crystallographic data. ${ }^{15}$ Interestingly, CuZnSOD does not display NiR activity.

\section{Identification of intramolecular electron and proton transfer pathways}

The CuNiR enzyme reaction requires that one electron and two protons are supplied to the catalytic T2Cu centre and it has been demonstrated that this occurs in a coupled (PCET) manner. ${ }^{25}$
Spectroscopic and mutational studies showed that electrons are transferred from physiological redox partner proteins such as azurin, pseudoazurin or cytochrome $c_{551}$ to reduce the $\mathrm{T} 1 \mathrm{Cu}$ centre. Intramolecular ET occurs between the $\mathrm{Cu}$ sites to deliver the electron to the $\mathrm{T} 2 \mathrm{Cu}$ centre, in the process reoxidising the T1Cu. The pathway for intramolecular ET was identified as a Cys-His bridge between ligating residues of the two $\mathrm{Cu}$ centres, providing a facile through-bond pathway.

T1Cu site mutations have been characterised revealing effects upon enzyme colour, redox potential and ET. A M150E mutation in $A f \mathrm{NiR}$ resulted in a protein binding $\mathrm{Zn}$ to the $\mathrm{T} 1 \mathrm{Cu}$ site $^{39}$ with a 1000 -fold loss of activity, while a C130A mutation in $A x N i R$ led to a vacant $\mathrm{T} 1 \mathrm{Cu}$ site $^{23}$ and abolition of activity.

Analysis of high resolution crystal structures led to proposals for proton channels connecting the protein surface (and bulk solvent) with the T2Cu site. A 'primary' proton channel in AxNiR linked the T2Cu site residue Asp ${ }_{\mathrm{CAT}}$ with the surface via a wellordered network of water molecules. ${ }^{42} \mathrm{~A}$ 'secondary' channel was later identified in a structure at high $\mathrm{pH}$ where residues Asn90, Asn107 and Ala131 together with water molecules also provide a H-bonding network to the surface. ${ }^{43}$ Supporting evidence was provided from activity and structural work on mutated enzymes. For example, a H254F mutation abolished the 'primary' channel yet retained near-native levels of activity. In contrast the N90S variant targeting the secondary channel lowered activity by $70 \%$. These data led to the proposal that this secondary channel was in fact the most important route for protons. ${ }^{22,25}$ Similarly, the ET pathway has been investigated by structural and related studies on mutants. As well as the C130A AxNiR mutation described above, a H129V mutation in AxNiR resulted in an unprecedented bis-His T2Cu binding site ${ }^{63}$ while disrupting the Cys-His bridge leading to a complete loss of enzyme activity.

\section{The structure of the T2Cu-NO species}

All crystal structures of CuNiR-NO complexes have revealed a side-on binding mode to T2Cu, Fig. 3C. ${ }^{18,45,55}$ Structures have been determined of NO complexes by several approaches: (i) NO-soaking into AfNiR crystals, ${ }^{45}$ (ii) endogenously present NO, in crystals grown from protein isolated from Achromobacter cycloclastes cells grown under denitrifying conditions ${ }^{18}$ and (iii) produced from nitrite in situ by X-ray driven catalysis using 'multiple-structure one crystal' (MSOX) serial crystallography. ${ }^{55}$ The structures determined by each method consistently show side-on binding with near-equidistant bond lengths to $\mathrm{Cu}$ for the $\mathrm{N}$ and $\mathrm{O}$ atoms and reveal that bound NO interacts with active site residues. Several issues regarding the NO complex remain challenging to address from the electron density alone. The electron density for the $\mathrm{N}$ and $\mathrm{O}$ atoms is very similar and structures have been determined with different assignments of the density peaks modelled. ${ }^{18,45,55}$ Consideration of bonding further suggests that the NO molecule interacts with Asp CAT which adopts its 'proximal' position in the product complex. Similarly, crystal structures are not yet able to give a definitive answer to the identification of the side-on NO complex as $\mathrm{Cu}(\mathrm{I})-\mathrm{NO}^{\bullet}$ or $\mathrm{Cu}(\mathrm{II})-\mathrm{NO}^{-}$. 
An outstanding mystery is the suggestion that solution spectroscopic data supports an end-on mode of NO binding $[\mathrm{Cu}-\mathrm{N}-\mathrm{O}]$ rather than side-on binding. In particular, ENDOR data $^{64}$ of native and the $\mathrm{I} 289 \mathrm{~V}$ and $\mathrm{I} 257 \mathrm{~A}$ mutants of $R s \mathrm{NiR}$ suggests a $\mathrm{Cu}-\mathrm{N}-\mathrm{O}$ angle of $160^{\circ}$ in native $R s \mathrm{NiR}$ with magnetic interaction of $\mathrm{O}$ with the $\mathrm{C}^{\delta 1}$ atom of Ile257. Simulations of the complex show 3-10 kcal mol ${ }^{-1}$ energetic preference for the end-on form. ${ }^{65}$ A subsequent EPR study of model compound analogues found a clear dependence of $g_{z}$ upon the $\mathrm{Cu}-\mathrm{N}-\mathrm{O}$ angle. ${ }^{66}$ Taken together with the previous EPR data of $R s \mathrm{NiR},{ }^{64}$ this work suggested that a strongly bent $\left(\sim 136^{\circ}\right) \mathrm{Cu}-\mathrm{N}-\mathrm{O}$ binding geometry is feasible in CuNiRs. One proposal from computational simulation was that Ile257 dictates the side-on binding mode observed in structures with the proposal that a small structural change when the protein is in solution would allow the end-on binding mode to be sterically feasible. ${ }^{67}$

\section{Surface properties and intermolecular electron transfer}

The electrostatic surfaces of CuNiRs are variable, with distinct differences between the blue and green classes of 2 domain enzymes. This, together with comparable analysis of the electrostatic surfaces of the partner proteins ${ }^{68}$ provides a rationale for the observed specificity of CuNiRs from different species for their cognate electron donors. ${ }^{68}$ Azurins reacted rapidly with blue CuNiRs but slowly with green CuNiRs. In contrast, pseudoazurin reacted effectively with either colour of CuNiR. Notably Af NiR (green) has a strong surface negative charge complementing the positive charge of the pseudoazurin complementary surface. ${ }^{68}$ Moreover, a common structural feature of CuNiRs is a hydrophobic patch on the enzyme surface near to the location of the $\mathrm{T} 1 \mathrm{Cu}$ centre, which has been proposed to form part of the charged protein-protein interface in the ET complex. ${ }^{69,70}$

Identifying the precise route(s) of intermolecular ET between the redox centre of the electron donor protein $(\mathrm{T} 1 \mathrm{Cu}$ or haem $\mathrm{Fe}$ ) and the CuNiR T1Cu centre is more challenging, in part due to the difficulty of obtaining crystal structures of transient ET complexes. Mutational analysis of putative pathway residues have provided insights. For example, a W138H mutation in $A x$ NiR produced a large drop in activity with the physiological redox partner azurin but retained full activity with the artificial electron donor methyl viologen. ${ }^{36}$ This supported a role for Trp138 in intermolecular ET, consistent with a docking model of the azurin-AxNiR complex which positioned Tyr197 close to the azurin T1Cu ligand His117. Tyr197 is close to Trp138 which is adjacent in sequence to a $\mathrm{T} 1 \mathrm{Cu} \mathrm{His}$ of $A x \mathrm{NiR}^{36}$

\section{Structural characterisation of complexes between CuNiRs and redox partners}

Structural characterisation of the ET complexes between CuNiRs and their partner proteins have remained elusive due to the transient nature of the complexes. Computational docking and mutagenesis have attempted to identify interface regions between CuNiRs and their specific azurin, pseudoazurin or $c$-type cytochrome partners e.g. ${ }^{67}$ Paramagnetic nuclear magnetic resonance (NMR) data have been used to characterise the interacting region in the complex between $A f \mathrm{NiR}$ and its partner pseudoazurin $[\mathrm{Paz}] .^{71}$ In this case, distance restraints derived from NMR data of gadolinium added to engineered surface cysteines were used to restrain computational docking simulations. The resulting structural model positions the T1Cu atoms of Paz and Af NiR some $15.5( \pm 0.5) \AA$ apart.

One crystal structure available for such an ET complex is that between $A x \mathrm{NiR}$ and a functional partner protein, $\mathrm{Cyt}_{c 551}$, at 1.7 A resolution ${ }^{49}$ (PDB 2ZON). This CuNiR has been shown to accept electrons either from azurin, psuedoazurin or a cytochrome electron donor. In the binary $A x \mathrm{NiR}-\mathrm{Cyt}_{c 551}$ complex, the edge of the haem moiety lies some $10.5 \AA$ from $\mathrm{T} 1 \mathrm{Cu}$ in an arrangement likely to promote efficient intermolecular ET, Fig. 5A. The protein-protein interface involves the previously proposed hydrophobic patch surrounded by a semicircle of interface water molecules. ${ }^{49}$ Analysis of the structure suggested the main ET route to be from the haem CBC methyl carbon through space to Pro88 of the CuNiR. Through-bond ET then proceeds to the adjacent T1Cu ligand His89.

Recently, a heterogeneous complex between $A x \mathrm{NiR}$ and a pseudoazurin from $H$. denitrificans as the electron donor was solved at $3.0 \AA$ resolution (PDB 5B1J). The intermolecular contact at the hydrophobic patches adjacent to the $\mathrm{T} 1 \mathrm{Cu}$ sites positions the $\mathrm{Cu}$ centres of the two proteins to within $\sim 16 \AA$. The solvent-exposed His81 Cu-ligand of the pseudoazurin lies $\sim 2.6 \AA$ from the Ala86 oxygen atom of $A x \mathrm{NiR}$, an arrangement that would allow through-space ET between the proteins, ${ }^{72}$ Fig. $5 \mathrm{~B}$.

\section{3-Domain fused CuNiRs}

A recent development has been the discovery of CuNiRs containing additional domains. The first example was the structure of the hexameric CuNiR from Hyphomicrobium denitrificans (HdNiR), ${ }^{73}$ determined at $2.2 \AA$ resolution, ${ }^{74}$ Fig. 1. $H d \mathrm{NiR}$ has high sequence homology to AniA, while the structure revealed a novel additional $\mathrm{N}$-terminal cupredoxin domain, containing an additional $\mathrm{T} 1 \mathrm{Cu}\left(\mathrm{T} 1 \mathrm{Cu}_{\mathrm{N}}\right)$ centre. The extended enzyme forms a $340 \mathrm{kDa}$ hexameric prism-shaped oligomer. Interestingly, the additional $\mathrm{T} \mathrm{Cu}_{\mathrm{N}}$ cupredoxin domain has low sequence homology to the other cupredoxin domains of $H d \mathrm{NiR}$ but high homology with those of Af NiR. The separation of the $\mathrm{T}_{1 C \mathrm{Cu}_{\mathrm{N}}}$ centres is $14 \AA$ in a head to head arrangement, suggesting that ET proceeds by initial reduction of $\mathrm{T} \mathrm{Cu}_{\mathrm{N}}$ by $\mathrm{Cyt}_{c 550}$ followed by ET between $\mathrm{T}^{\mathrm{C}} \mathrm{Cu}_{\mathrm{N}}$ and $\mathrm{T} 1 \mathrm{Cu}_{\mathrm{C}}$, Fig. 6A. The additional cupredoxin domain in $H d \mathrm{NiR}$ may not be involved in the catalytic mechanism ${ }^{74}$ due to the large distance separating it from the $\mathrm{T} 2 \mathrm{Cu}$ centre where catalysis occurs. Subsequent bioinformatics analysis led to the identification of other $\mathrm{N}$ - and C-terminal 3-domain CuNiRs. ${ }^{9}$ The C-terminallyextended enzymes possess an additional haem-cytochrome domain. A crystal structure of a C-terminally extended CuNiR from Pseudoalteromonas haloplanktis (PhNiR) was deposited in the Protein Data Bank in 2008 (PDB 2ZOO) but remains unpublished. The first detailed and published structural analysis of a C-terminally extended CuNiR, came from the atomic resolution (1.01 $\AA$ ) structure of the 499 residue CuNiR from Ralstonia picketti $(R p \mathrm{NiR})$ by Hasnain and co-workers. ${ }^{75}$ The $1.01 \AA$ resolution structure of $R p \mathrm{NiR}^{75}$ revealed a domain binding motif that positioned the T1Cu and Fe atoms only $10.6 \AA$ apart, notably 


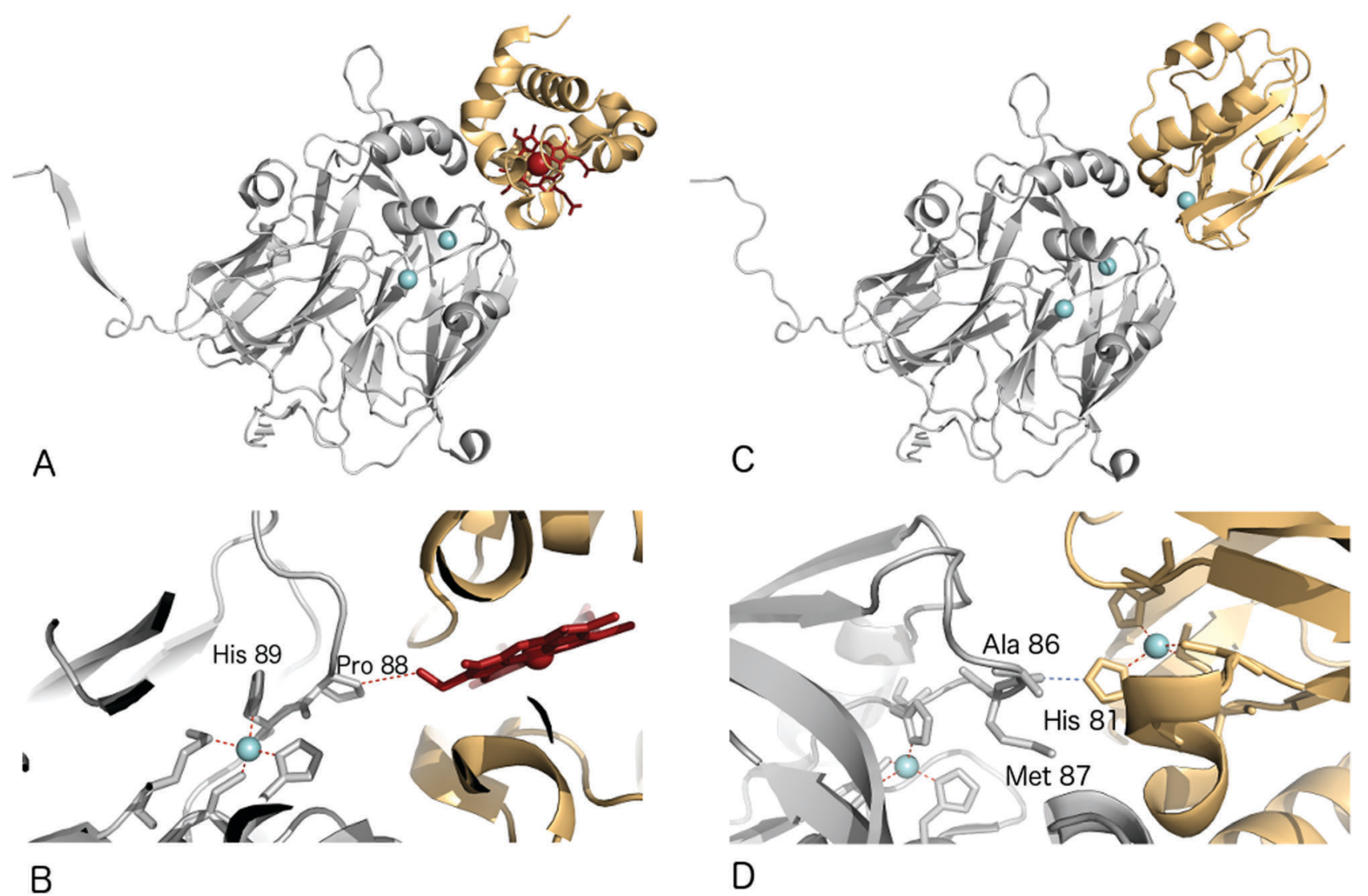

Fig. 5 Structures of electron transfer complexes between $\mathrm{CuNiRs}$ and electron transfer proteins. Cu atoms are shown as cyan spheres, while the haem group of cyt. $C_{551}$ is represented using red sticks (A) structure of the proposed electron transfer complex between $A x N i R$ (gray) and cyt. $C_{551}$ (orange); (B) the interface region of the complex shown in (a), note the close contact between Pro88 of AxNiR and the haem edge of cyt. $C_{551}$. (C) Structure of the proposed electron transfer complex between AxNiR (gray) and pseudoazurin from $H$. denitrificans (PAz, orange); (D) interface region of the complex shown in (C) here note the close contact between Ala86 of AxNiR and the T1Cu ligand His81 in Paz.

closer than the separation of centres in the AxNiR-Cyt ${ }_{c 551}$ complex, Fig. 5 and 6. A series of water molecules were present between the cytochrome domain and the surface above the T1Cu site, suggesting a role in electronic coupling across the interface. This hypothesis was tested by structural and functional analysis of sitedirected mutants which confirmed the roles of Met92 and Pro93 in interface ET. As well as the differences in domain structure, notable differences are apparent between $R p \mathrm{NiR}$ and the 2-domain NiRs in the vicinity of the catalytic T2Cu centre. In contrast to 2-domain NiRs where the T2Cu-bound water is $\mathrm{H}$-bonded to Asp $\mathrm{CAT}_{\mathrm{CAT}}$ and $\mathrm{His}_{\mathrm{CAT}}$, in RpNiR this water instead forms an $\mathrm{H}$-bond to $\mathrm{Asp}_{\mathrm{CAT}}$ and a second water molecule. In $P h \mathrm{NiR}$, the water is only H-bonded to Asp $\mathrm{CAT}_{\text {. }}$.

Notably, in the substrate binding channel of $R p \mathrm{NiR}$, a Tyr residue acts to 'plug' the substrate binding channel, excluding water molecules. ${ }^{75}$ The atomic resolution structure of $R p$ NiR provided clear evidence for the observed preference for nitrite binding to reduced $\mathrm{T} 2 \mathrm{Cu}$ in this enzyme, rather than the preferred oxidised state in 2-domain CuNiRs.

\section{Membrane associated CuNiRs}

The crystal structure of the soluble domain of the outer membrane AniA protein from Neisseria gonorrhoeae was determined in $2002 .{ }^{44}$
The AniA protein has around half the specific activity of $A f \mathrm{NiR}$, is essential for growth in low-oxygen conditions with nitrite present and protects against human-sera killing of the pathogen. The soluble domain has a similar fold to the typical CuNiRs but has two shortened loops, with one loop possibly related to interactions with a membrane anchored azurin electron donor and the other likely to interact with the membrane itself. The $\mathrm{Cu}$ centres in AniA are similar to those of 2-domain CuNiRs, but with a visible colour intermediate between that of green and blue sites. While bioinformatics identified related proteins to AniA across a range of species, further structures have not yet been forthcoming.

\section{Variations on the classical CuNiR structure and further classification of CuNiRs}

In the vicinity of the metal centres, CuNiRs have been divided into classes based on the length of the two loops, the linker loop between the cupredoxin domains forming a monomer and the 'tower loop' adjacent to the $\mathrm{T} 1 \mathrm{Cu}$ site. ${ }^{44}$ The majority of structures are of class I enzymes, while class II includes AniA. ${ }^{44}$ Some recently discovered CuNiRs fall between these two classes with intermediate length loops, e.g. GkNiR. Several CuNiRs from thermophilic bacteria have been structurally characterised. The structure of Geobacillus kaustophilus HTA426 CuNiR (GkNiR) ${ }^{51}$ 
A

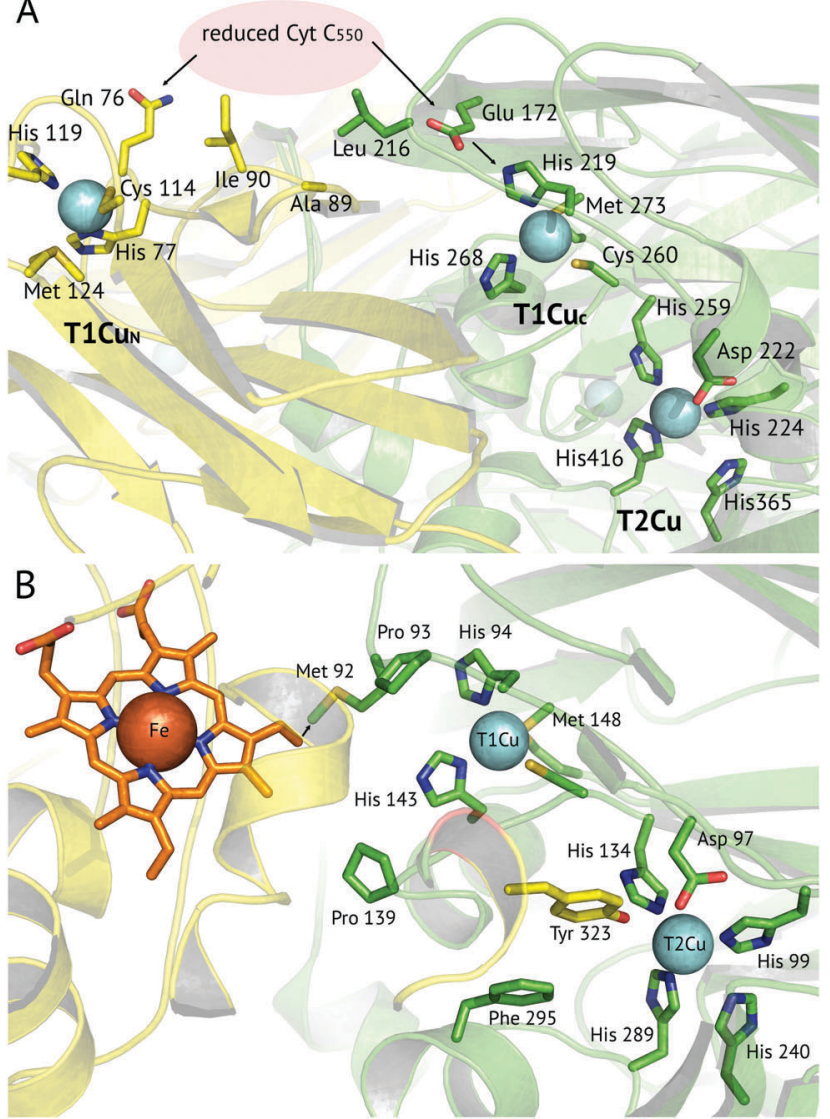

Fig. 6 Proposed electron transfer routes between the redox centres of 3-domain CuNiRs. In (A) HdNiR the external electron donor partner protein cyt. $C_{550}$ is proposed to bind to a hydrophobic patch spanning the $\mathrm{N}$-terminal (near Ala89, Ile90) and cupredoxin domains (near Leu216), where it is positioned for electron transfer to both the $\mathrm{T}_{1} \mathrm{Cu}_{\mathrm{N}}$ and $\mathrm{T} 1 \mathrm{Cu}_{\mathrm{C}}$ sites (indicated by arrows). ${ }^{74}$ In (B) RpNiR, the proposed internal electron transfer route is from the haem (CBC atom) to Met92 and to the T1Cu site. ${ }^{75}$ Interface and T2Cu water molecules have been omitted from the figures for clarity.

revealed a novel 28 residue additional $\alpha$-helical region close to the N-terminus (residues 41-68). Other notable features of $G k \mathrm{NiR}$ include the presence of a Val residue in place of Ile $_{\mathrm{CAT}}$ and differences in the hydrogen bonding network around the $\mathrm{T} 2 \mathrm{Cu}$ centre.

Much of the structural data presented above has come from single, static crystal structures. Recent developments in X-ray sources, rapid detectors and data handling have allowed the determination of both 'damage free' single structures from large numbers of microcrystals and also multiple (potentially hundreds of) sequential datasets from just one protein crystal, making it possible to follow reactions in crystallo. Both approaches show promise for determining structures of relevant catalytic intermediates.

\section{Insights from multiple-structures one crystal (MSOX) serial crystallography}

Multiple Structures from One Crystal (MSOX) is a data collection technique which uses solvated electrons generated during X-ray diffraction experiments to drive reactions requiring electron transfer. ${ }^{76}$ By taking sequential diffraction datasets over the same volume of one crystal it is possible to observe a reaction, occurring through a series of high resolution crystal structures with progressively increasing X-ray dose, Fig. 7. For NiRs, this approach was used to obtain 3 (low, medium and high-dose) datasets from tobacco assimilatory NiR, a Fe-S cluster and sirohaem containing protein that converts nitrite to ammonium. ${ }^{77} \mathrm{~A}$ series of this sort for a CuNiR, comprising 45 consecutive datasets collected in $19 \mathrm{~s}$ each for $A c \mathrm{NiR}$, between $1.07 \AA ̊$ and $1.62 \AA$ A resolutions, clearly showed conversion of bound $\mathrm{NO}_{2}^{-}$, to side-on $\mathrm{NO}^{55}$ within the crystal. At the end of the 45 structure series, a $\mathrm{Cu}(\mathrm{II})$ species with bound water is observed after loss of the NO ligand. Crystal structures are not yet able to give a definitive answer to the identification of the observed side-on NO complex as $\mathrm{Cu}(\mathrm{I})-\mathrm{NO}^{\bullet}$ or $\mathrm{Cu}(\mathrm{II})-\mathrm{NO}^{\bullet}$.

Little to no change to the overall fold of the enzyme or in the vicinity of the T1Cu site were seen throughout the MSOX series. The low dose atomic resolution starting structure exhibited a previously unseen dual conformation of $\mathrm{NO}_{2}{ }^{-}$, in "top-hat" and "side-on" bidentate orientations, of which the top-hat conformation matches the vertical substrate coordination from 'radiation-damagefree' XFEL structures, ${ }^{54,58}$ corroborating the idea that this vertical binding mode represents the initial nitrite binding position. Overall, the 45-dataset MSOX series demonstrated several structural changes at the T2Cu site, Fig. 7. Starting with the dual conformation nitrite

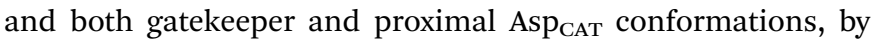
dataset four the series showed nitrite adopting a single side-on conformation and increasing proximal Asp $\mathrm{AAT}_{\mathrm{CA}}$ occupancy, lending credence to the operation of the sensor loop in response to

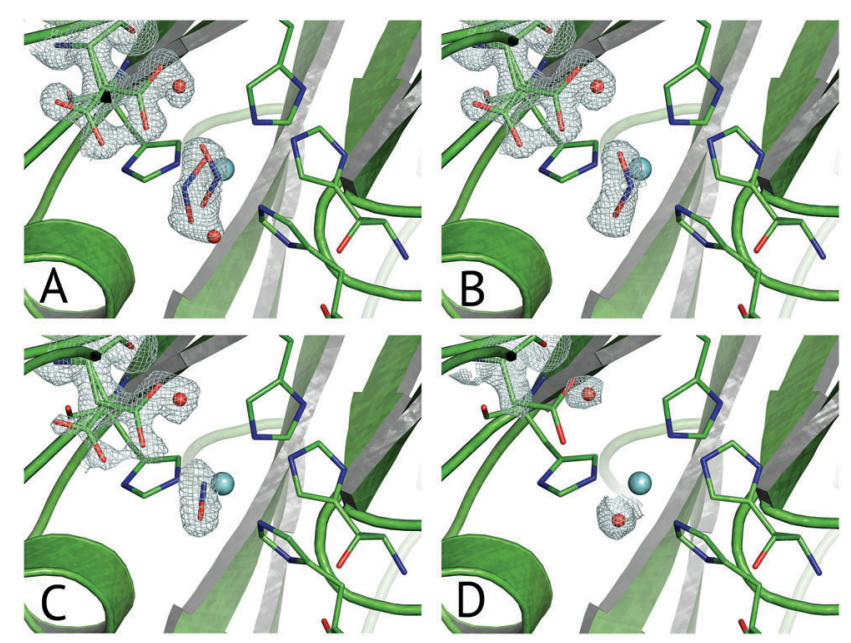

Fig. 7 Selected frames from the 45 -frame MSOX structural movie of AcNiR catalysis at $100 \mathrm{~K}^{55}$ (A) The starting nitrite-bound state with partial occupancies in the top-hat and side-on modes (dataset 1, PDB 5i6k); (B) fully side-on nitrite (dataset 4, PDB 5i6l); (C) side-on nitric oxide product complex (dataset 17, PDB 5i6n); (D) water rebinding to the T2Cu following dissociation of $\mathrm{NO}$ (dataset 40, PDB 5i6k). Electron density is shown, contoured at $0.53-0.36 \mathrm{e}^{-} \AA^{-3}$, for the ligands and the

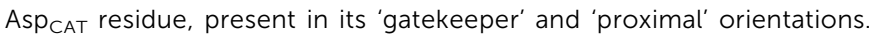
The T2Cu atom is depicted by the cyan sphere and water molecules by red spheres. 
the copper oxidation states during catalysis. ${ }^{23}$ By dataset eleven a second previously unseen conformation was observed, with either $\mathrm{NO}_{2}{ }^{-}$, $\mathrm{NO}$ or a $\mathrm{H}_{2} \mathrm{O}$ molecule at the $\mathrm{T} 2 \mathrm{Cu}$, indicative of catalytic turnover in the crystal. The changes in gatekeeper and

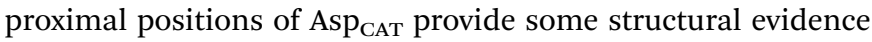
for the role of $\mathrm{Asp}_{\mathrm{CAT}}$ in substrate delivery and product release.

\section{XFEL structures of intact redox states of CuNiRs by serial femtosecond crystallography}

Reduction of metalloproteins by X-ray generated solvated electrons has been well-characterised, presents a major challenge for structural biology of such proteins, ${ }^{78,79}$ and has been demonstrated to occur in CuNiRs. ${ }^{27}$ Various online spectroscopic techniques have been developed to monitor the redox state of metals in crystals. ${ }^{80-82}$ Strategies to mitigate such reduction include merging of composite, low dose partial datasets ${ }^{83}$ or helical data collection approaches. ${ }^{84}$ Use of rapid X-ray detectors and cryogenic temperatures - typically $100 \mathrm{~K}$ - minimises but does not eliminate the effects of photoreduction or radiation damage to crystals. However, intact fully-oxidised structures may require the use of femtosecond X-ray pulses that can only be provided with sufficient brilliance by an X-ray free electron laser (XFEL). ${ }^{85}$ The first CuNiR XFEL structures at room temperature were recently obtained using the Spring-8 Compact Free Electron Laser (SACLA). ${ }^{54,58}$

Comparison of the $1.43 \AA$ resolution serial femtosecond crystallography (SFX) structure of resting state $G t \mathrm{NiR}^{58}$ with conventional synchrotron radiation (SRX) structures revealed a $10^{\circ}$ rotation of the imidazole ring of $\mathrm{His}_{\mathrm{CAT}}$, in the SRX data in relation to the SFX structure. This led to the suggestion that His $_{\mathrm{CAT}}$ may function as a proton-relay switch, whereby $\mathrm{T} 2 \mathrm{Cu}$ reduction causes His $_{\mathrm{CAT}}$ rotation thus altering the H-bonding

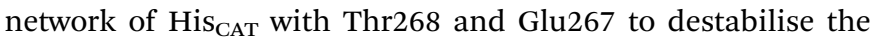
positive charge of $\mathrm{His}_{\mathrm{CAT}}$ and facilitate proton transfer to the bridging water.

Subsequently, SFX structures were determined of Alcaligenes faecalis NiR (AfNiR) in its resting and nitrite bound (PDB 5D4I) states at $2.03 \AA$ and $1.60 \AA$ A resolutions, respectively. ${ }^{54}$ The SFX structure of intact nitrite bound $A f \mathrm{NiR}$ revealed a single, vertical 'top-hat' binding mode of $\mathrm{NO}_{2}{ }^{-}$compared to the side on conformation typically observed in SRX structures, ${ }^{18}$ suggesting the conformational change to side on $\mathrm{NO}_{2}{ }^{-}$results from photoreduction of the metal centres. Af NiR, as in GtNiR, shows a conformational change in His $_{\mathrm{CAT}}$ in photoreduced SRX structures compared to oxidised SFX structures. However, unlike GtNiR

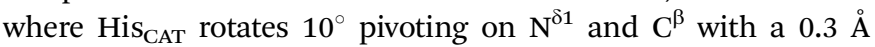

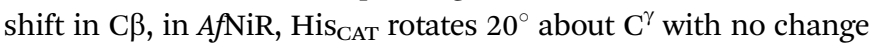
in $\mathrm{C} \beta$, switching the H-bonding partner of His ${ }_{\mathrm{CAT}} \mathrm{N}^{\varepsilon 2}$ from the Glu279 carbonyl to the hydroxyl of Thr280 which is both a longer and weaker H-bond, Fig. 8. Based on this conformational change between SFX and SRX structure ${ }^{54}$ an updated reaction mechanism for CuNiRs was suggested in which nitrite binds to the $\mathrm{T} 2 \mathrm{Cu}$ and is protonated by Asp $\mathrm{CAT}_{\mathrm{CA}}$. This is followed by intramolecular ET to give side-on nitrite and rotation of $\mathrm{His}_{\mathrm{CAT}}$, where weaker $\mathrm{H}$-bonds

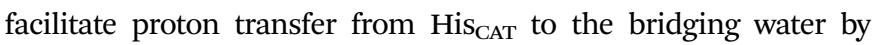
destabilising the positive charge of His ${ }_{\mathrm{CAT}}$. With this the necessary

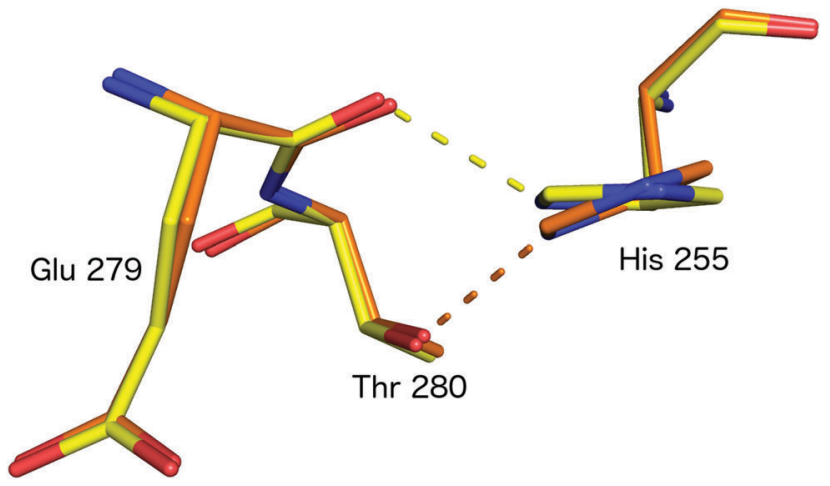

Fig. 8 His $\mathrm{CAT}$ rotation in the proposed redox coupled proton transfer mechanism derived from comparison of XFEL (SFX; PDB 4YSC) and synchrotron radiation (SRX; PDB 4YSE) structures of AfNiR. ${ }^{54}$ Note the $\mathrm{H}$-bond

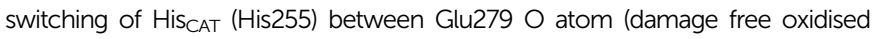
XFEL structure, yellow) and Thr280 (reduced SRX structure, orange).

second proton can be delivered to form NO in either end-on or side-on binding modes. However, the recently published MSOX series ${ }^{55}$ showing $\mathrm{X}$-ray induced ligand turnover from $\mathrm{NO}_{2}{ }^{-}$to sideon NO to water shows no change in the H-bond distances between His $_{\mathrm{CAT}}$ and Glu279 (2.7 Å) between low and high X-ray doses and a gradual increase in the bond length between His $_{\mathrm{CAT}}$ and Thr280 with increasing dose (2.8 $\AA$ at 0.69 MGy and $3.1 \AA$ at 27.60 MGy).

\section{Outlook and remaining questions}

Several exciting new discoveries of CuNiR enzymes together with methodological developments have taken place in recent years. The advent of rapid mixing technologies at XFEL sources may allow time-resolved structural analysis of the CuNiR reaction with damage-free structures for reaction intermediates. The everincreasing number of sequenced genomes promises the discovery of new variations of CuNiRs with differing domain structures. However, several outstanding questions remain that structural analysis will play a key role in addressing. For example, the protonation states of the important 'catalytic residues' have yet to be unequivocally determined for all stages of the reaction mechanism. Neutron diffraction - another way to obtain room temperature radiation-damage free structures - may help provide this information in the future and its potential for studying CuNiRs, in combination with high resolution X-ray structures, has already been shown. ${ }^{86}$ Establishing the precise chemical nature of the sideon NO intermediate also remains challenging as do the routes of substrate access and product escape. While significant insights have been gained from the current structures of protein-protein electron transfer complexes, improved structural resolution is required to clarify details of the emerging picture. The dynamic behaviour of CuNiRs is clearly of vital importance and can be addressed by combining structural data, measured at different temperatures, with molecular dynamics and QM/MM simulations.

\section{Acknowledgements}

The work was supported by BBSRC grant awards BB/M020924/1 to RWS, BB/M022714/1 to MH and by Leverhulme Trust grant 
RPG-2014-355 to $\mathrm{MH}$ and RWS. We acknowledge Professors S. S. Hasnain and R. R. Eady and Dr S. Antonyuk for fruitful discussions of CuNiRs over many years.

\section{References}

1 R. Knowles, Denitrification, Microbiol. Rev., 1982, 46, 43-70.

2 W. G. Zumft, Cell biology and molecular basis of denitrification, Microbiol. Mol. Biol. Rev., 1997, 61, 533-616.

3 R. R. Eady and S. S. Hasnain, in Comprehensive Coordination Chemistry II: Bio-Coordination Chemistry, ed. L. T. W. Que, Elsevier, Oxford, 2003, vol. 8, pp. 759-786.

4 A. J. Thomson, G. Giannopoulos, J. Pretty, E. M. Baggs and D. J. Richardson, Biological sources and sinks of nitrous oxide and strategies to mitigate emissions, Philos. Trans. $R$. Soc., B, 2012, 367, 1157-1168.

5 Metalloenzymes in Denitrification: Applications and Environmental Impacts, ed. I. Moura, J. Moura, S. Pauleta and L. Maia, The Royal Society of Chemistry, 2017.

6 J. W. Godden, S. Turley, D. C. Teller, E. T. Adman, M. Y. Liu, W. J. Payne and J. LeGall, The 2.3 ̊ X-ray structure of nitrite reductase from Achromobacter cycloclastes, Science, 1991, 253, 438-442.

7 E. T. Adman, in Topics in Molecular and Structural Biology: Metalloproteins, Part 1: Metal proteins with redox roles, ed. P. M. Harrison, MacMillan, New York, 1985, vol. 6, pp. 1-42.

8 A. C. Merkle and N. Lehnert, Binding and activation of nitrite and nitric oxide by copper nitrite reductase and corresponding model complexes, Dalton Trans., 2012, 41, 3355-3368.

9 M. J. Ellis, J. G. Grossmann, R. R. Eady and S. S. Hasnain, Genomic analysis reveals widespread occurrence of new classes of copper nitrite reductases, J. Biol. Inorg. Chem., 2007, 12, 1119-1127.

10 R. R. Eady, S. V. Antonyuk and S. S. Hasnain, Fresh insight to functioning of selected enzymes of the nitrogen cycle, Curr. Opin. Chem. Biol., 2016, 31, 103-112.

11 K. C. Cheung, R. W. Strange and S. S. Hasnain, 3D EXAFS refinement of the $\mathrm{Cu}$ site of azurin sheds light on the nature of structural change at the metal centre in an oxidationreduction process: an integrated approach combining EXAFS and crystallography, Acta Crystallogr., Sect. D: Biol. Crystallogr., 2000, 56, 697-704.

12 E. I. Solomon, Spectroscopic methods in bioinorganic chemistry: blue to green to red copper sites, Inorg. Chem., 2006, 45, 8012-8025.

13 P. Hosseinzadeh, S. Tian, N. M. Marshall, J. Hemp, T. Mullen, M. J. Nilges, Y. G. Gao, H. Robinson, D. A. Stahl, R. B. Gennis and Y. Lu, A Purple Cupredoxin from Nitrosopumilus maritimus Containing a Mononuclear Type 1 Copper Center with an Open Binding Site, J. Am. Chem. Soc., 2016, 138, 6324-6327.

14 S. Ghosh, X. Xie, A. Dey, Y. Sun, C. P. Scholes and E. I. Solomon, Thermodynamic equilibrium between blue and green copper sites and the role of the protein in controlling function, Proc. Natl. Acad. Sci. U. S. A., 2009, 106, 4969-4974.
15 R. W. Strange, L. M. Murphy, F. E. Dodd, Z. H. Abraham, R. R. Eady, B. E. Smith and S. S. Hasnain, Structural and kinetic evidence for an ordered mechanism of copper nitrite reductase, J. Mol. Biol., 1999, 287, 1001-1009.

16 E. Adman and M. E. Murphy, Copper Nitrite Reductase, Handbook of Metalloproteins, 2006, vol. 6.

17 E. T. Adman, J. W. Godden and S. Turley, The structure of copper-nitrite reductase from Achromobacter cycloclastes at five $\mathrm{pH}$ values, with $\mathrm{NO}_{2}{ }^{-}$bound and with type II copper depleted, J. Biol. Chem., 1995, 270, 27458-27474.

18 S. V. Antonyuk, R. W. Strange, G. Sawers, R. R. Eady and S. S. Hasnain, Atomic resolution structures of resting-state, substrate- and product-complexed Cu-nitrite reductase provide insight into catalytic mechanism, Proc. Natl. Acad. Sci. U. S. A., 2005, 102, 12041-12046.

19 M. J. Ellis, M. Prudencio, F. E. Dodd, R. W. Strange, G. Sawers, R. R. Eady and S. S. Hasnain, Biochemical and crystallographic studies of the Met144Ala, Asp92Asn and His254Phe mutants of the nitrite reductase from Alcaligenes xylosoxidans provide insight into the enzyme mechanism, J. Mol. Biol., 2002, 316, 51-64.

20 E. I. Solomon, D. E. Heppner, E. M. Johnston, J. W. Ginsbach, J. Cirera, M. Qayyum, M. T. Kieber-Emmons, C. H. Kjaergaard, R. G. Hadt and L. Tian, Copper active sites in biology, Chem. Rev., 2014, 114, 3659-3853.

21 M. J. Boulanger and M. E. Murphy, Directing the mode of nitrite binding to a copper-containing nitrite reductase from Alcaligenes faecalis S-6: characterization of an active site isoleucine, Protein Sci., 2003, 12, 248-256.

22 M. A. Hough, R. R. Eady and S. S. Hasnain, Identification of the proton channel to the active site type $2 \mathrm{Cu}$ center of nitrite reductase: structural and enzymatic properties of the His254Phe and Asn90Ser mutants, Biochemistry, 2008, 47, 13547-13553.

23 M. A. Hough, M. J. Ellis, S. Antonyuk, R. W. Strange, G. Sawers, R. R. Eady and S. S. Hasnain, High resolution structural studies of mutants provide insights into catalysis and electron transfer processes in copper nitrite reductase, J. Mol. Biol., 2005, 350, 300-309.

24 N. G. Leferink, R. R. Eady, S. S. Hasnain and N. S. Scrutton, Laser-flash photolysis indicates that internal electron transfer is triggered by proton uptake by Alcaligenes xylosoxidans copper-dependent nitrite reductase, FEBS J., 2012, 279, 2174-2181.

25 N. G. H. Leferink, C. Han, S. V. Antonyuk, D. J. Heyes, S. E. J. Rigby, M. A. Hough, R. R. Eady, N. S. Scrutton and S. S. Hasnain, Proton-Coupled Electron Transfer in the Catalytic Cycle of Alcaligenes xylosoxidans Copper-Dependent Nitrite Reductase, Biochemistry, 2011, 50, 4121-4131.

26 H. J. Wijma, L. J. C. Jeuken, M. P. Verbeet, F. A. Armstrong and G. W. Canters, A random-sequential mechanism for nitrite binding and active site reduction in copper-containing nitritereductase, J. Biol. Chem., 2006, 281, 16340-16346.

27 M. A. Hough, S. V. Antonyuk, R. W. Strange, R. R. Eady and S. S. Hasnain, Crystallography with online optical and X-ray absorption spectroscopies demonstrates an ordered mechanism in copper nitrite reductase, J. Mol. Biol., 2008, 378, 353-361. 
28 Ł. Krzemiński, L. Ndamba, G. W. Canters, T. J. Aartsma, S. D. Evans and L. J. C. Jeuken, Spectroelectrochemical Investigation of Intramolecular and Interfacial ElectronTransfer Rates Reveals Differences Between Nitrite Reductase at Rest and During Turnover, J. Am. Chem. Soc., 2011, 133, 15085-15093.

29 M. Lintuluoto and J. M. Lintuluoto, DFT Study on Nitrite Reduction Mechanism in Copper-Containing Nitrite Reductase, Biochemistry, 2016, 55, 210-223.

30 M. Lintuluoto and J. M. Lintuluoto, DFT Study on Enzyme Turnover Including Proton and Electron Transfers of Copper-Containing Nitrite Reductase, Biochemistry, 2016, 55, 4697-4707.

31 Y. Li, M. Hodak and J. Bernholc, Enzymatic Mechanism of Copper-Containing Nitrite Reductase, Biochemistry, 2015, 54, 1233-1242.

32 S. Ghosh, A. Dey, Y. Sun, C. P. Scholes and E. I. Solomon, Spectroscopic and computational studies of nitrite reductase: proton induced electron transfer and backbonding contributions to reactivity, J. Am. Chem. Soc., 2009, 131, 277-288.

33 S. A. De Marothy, M. R. Blomberg and P. E. Siegbahn, Elucidating the mechanism for the reduction of nitrite by copper nitrite reductase-A contribution from quantum chemical studies, J. Comput. Chem., 2007, 28, 528-539.

34 R. Silaghi-Dumitrescu, Copper-containing nitrite reductase: A DFT study of nitrite and nitric oxide adducts, J. Inorg. Biochem., 2006, 100, 396-402.

35 M. J. Boulanger and M. E. Murphy, Alternate substrate binding modes to two mutant (D98N and H255N) forms of nitrite reductase from Alcaligenes faecalis S-6: structural model of a transient catalytic intermediate, Biochemistry, 2001, 40, 9132-9141.

36 M. L. Barrett, R. L. Harris, S. Antonyuk, M. A. Hough, M. J. Ellis, G. Sawers, R. R. Eady and S. S. Hasnain, Insights into redox partner interactions and substrate binding in nitrite reductase from Alcaligenes xylosoxidans: crystal structures of the Trp138His and His313Gln mutants, Biochemistry, 2004, 43, 16311-16319.

37 F. Jacobson, A. Pistorius, D. Farkas, W. De Grip, O. Hansson, L. Sjolin and R. Neutze, pH dependence of copper geometry, reduction potential, and nitrite affinity in nitrite reductase, J. Biol. Chem., 2007, 282, 6347-6355.

38 E. T. Adman, J. E. Godden and S. Turley, The Structure of copper nitrite reductase from Achromobactor cycloclastes at $5 \mathrm{pH}$ values, with $\mathrm{NO}_{2}{ }^{-}$bound, and with type-2 $\mathrm{Cu}$ (II) depleted, J. Biol. Chem., 1995, 270, 27458-27474.

39 M. E. P. Murphy, S. Turley, M. Kukimoto, M. Nishiyama, S. Horinouchi, H. Sasaki, M. Tanokura and E. T. Adman, Structure of Alcaligenes faecalis Nitrite Reductase and a Copper Site Mutant, M150E, That Contains Zinc, Biochemistry, 1995, 34, 12107-12117.

40 F. E. Dodd, S. S. Hasnain, Z. H. L. Abraham, R. R. Eady and B. E. Smith, Structures of a Blue-Copper Nitrite Reductase and its Substrate-Bound Complex, Acta Crystallogr., Sect. D: Biol. Crystallogr., 1997, D53, 406-418.
41 M. E. P. Murphy, S. Turley and E. T. Adman, Structure of nitrite bound to copper-containing nitrite reductase from Alcaligenes faecalis, J. Biol. Chem., 1997, 272, 28455-28460.

42 F. E. Dodd, J. Van Beeumen, R. R. Eady and S. S. Hasnain, $\mathrm{X}$-ray structure of a blue-copper nitrite reductase in two crystal forms. The nature of the copper sites, mode of substrate binding and recognition by redox partner, J. Mol. Biol., 1998, 282, 369-382.

43 M. J. Ellis, F. E. Dodd, R. W. Strange, M. Prudencio, G. Sawers, R. R. Eady and S. S. Hasnain, X-ray structure of a blue copper nitrite reductase at high $\mathrm{pH}$ and in copper-free form at 1.9 A resolution, Acta Crystallogr., Sect. D: Biol. Crystallogr., 2001, 57, 1110-1118.

44 M. J. Boulanger and M. E. Murphy, Crystal structure of the soluble domain of the major anaerobically induced outer membrane protein (AniA) from pathogenic Neisseria: a new class of copper-containing nitrite reductases, J. Mol. Biol., 2002, 315, 1111-1127.

45 E. I. Tocheva, F. I. Rosell, A. G. Mauk and M. E. Murphy, Side-on copper-nitrosyl coordination by nitrite reductase, Science, 2004, 304, 867-870.

46 F. Jacobson, H. Guo, K. Olesen, M. Okvist, R. Neutze and L. Sjolin, Structures of the oxidized and reduced forms of nitrite reductase from Rhodobacter sphaeroides 2.4.3 at high pH: changes in the interactions of the type 2 copper, Acta Crystallogr., Sect. D: Biol. Crystallogr., 2005, 61, 1190-1198.

47 K. Paraskevopoulos, M. A. Hough, R. G. Sawers, R. R. Eady and S. S. Hasnain, The structure of the Met144Leu mutant of copper nitrite reductase from Alcaligenes xylosoxidans provides the first glimpse of a protein-protein complex with azurin II, J. Biol. Inorg. Chem., 2007, 12, 789-796.

48 E. I. Tocheva, F. I. Rosell, A. G. Mauk and M. E. Murphy, Stable copper-nitrosyl formation by nitrite reductase in either oxidation state, Biochemistry, 2007, 46, 12366-12374.

49 M. Nojiri, H. Koteishi, T. Nakagami, K. Kobayashi, T. Inoue, K. Yamaguchi and S. Suzuki, Structural basis of inter-protein electron transfer for nitrite reduction in denitrification, Nature, 2009, 462, 117-120.

50 T. J. Lawton, K. E. Bowen, L. A. Sayavedra-Soto, D. J. Arp and A. C. Rosenzweig, Characterization of a nitrite reductase involved in nitrifier denitrification, J. Biol. Chem., 2013, 288, 25575-25583.

51 Y. Fukuda, H. Koteishi, R. Yoneda, T. Tamada, H. Takami, T. Inoue and M. Nojiri, Structural and functional characterization of the Geobacillus copper nitrite reductase: involvement of the unique $\mathrm{N}$-terminal region in the interprotein electron transfer with its redox partner, Biochim. Biophys. Acta, 2014, 1837, 396-405.

52 Y. Fukuda, K. M. Tse, M. Lintuluoto, Y. Fukunishi, E. Mizohata, H. Matsumura, H. Takami, M. Nojiri and T. Inoue, Structural insights into the function of a thermostable copper-containing nitrite reductase, J. Biochem., 2014, 155, 123-135.

53 Y. Fukuda and T. Inoue, High-temperature and highresolution crystallography of thermostable copper nitrite reductase, Chem. Commun., 2015, 51, 6532-6535. 
54 Y. Fukuda, K. M. Tse, T. Nakane, T. Nakatsu, M. Suzuki, M. Sugahara, S. Inoue, T. Masuda, F. Yumoto, N. Matsugaki, E. Nango, K. Tono, Y. Joti, T. Kameshima, C. Song, T. Hatsui, M. Yabashi, O. Nureki, M. E. Murphy, T. Inoue, S. Iwata and E. Mizohata, Redox-coupled proton transfer mechanism in nitrite reductase revealed by femtosecond crystallography, Proc. Natl. Acad. Sci. U. S. A., 2016, 113, 2928-2933.

55 S. Horrell, S. V. Antonyuk, R. R. Eady, S. S. Hasnain, M. A. Hough and R. W. Strange, Serial crystallography captures enzyme catalysis in copper nitrite reductase at atomic resolution from one crystal, IUCrJ, 2016, 3, 271-281.

56 B. A. Wallace, Protein characterisation by synchrotron radiation circular dichroism spectroscopy, Q. Rev. Biophys., 2009, 42, 317-370.

57 J. Spence and E. Lattman, Imaging enzyme kinetics at atomic resolution, IUCrJ, 2016, 3, 228-229.

58 Y. Fukuda, K. M. Tse, M. Suzuki, K. Diederichs, K. Hirata, T. Nakane, M. Sugahara, E. Nango, K. Tono, Y. Joti, T. Kameshima, C. Song, T. Hatsui, M. Yabashi, O. Nureki, H. Matsumura, T. Inoue, S. Iwata and E. Mizohata, Redoxcoupled structural changes in nitrite reductase revealed by serial femtosecond and microfocus crystallography, J. Biochem., 2016, 159, 527-538.

59 N. G. Leferink, S. V. Antonyuk, J. A. Houwman, N. S. Scrutton, R. R. Eady and S. S. Hasnain, Impact of residues remote from the catalytic centre on enzyme catalysis of copper nitrite reductase, Nat. Commun., 2014, 5, 4395.

60 E. I. Tocheva, L. D. Eltis and M. E. P. Murphy, Conserved active site residues limit inhibition of a copper-containing nitrite reductase by small molecules, Biochemistry, 2008, 47, 4452-4460.

61 Y. Fukuda, K. M. Tse, Y. Kado, E. Mizohata, H. Matsumura and $\mathrm{T}$. Inoue, Insights into unknown foreign ligand in copper nitrite reductase, Biochem. Biophys. Res. Commun., 2015, 464, 622-628.

62 W. P. Michalski and D. J. D. Nicholas, Molecular characterization of a copper-containing nitrite reductase from Rhodopseudomonas sphaeroides from sp. denitrificans, Biochim. Biophys. Acta, 1985, 828, 130-137.

63 M. J. Ellis, S. V. Antonyuk, R. W. Strange, G. Sawers, R. R. Eady and S. S. Hasnain, Observation of an unprecedented Cu Bis-His site: crystal structure of the H129V mutant of nitrite reductase, Inorg. Chem., 2004, 43, 7591-7593.

64 O. M. Usov, Y. Sun, V. M. Grigoryants, J. P. Shapleigh and C. P. Scholes, EPR-ENDOR of the Cu(I)NO complex of nitrite reductase, J. Am. Chem. Soc., 2006, 128, 13102-13111.

65 S. Ghosh, A. Dey, O. M. Usov, Y. Sun, V. M. Grigoryants, C. P. Scholes and E. I. Solomon, Resolution of the spectroscopy versus crystallography issue for NO intermediates of nitrite reductase from Rhodobacter sphaeroides, J. Am. Chem. Soc., 2007, 129, 10310-10311.

66 K. Fujisawa, A. Tateda, Y. Miyashita, K. Okamoto, F. Paulat, V. K. Praneeth, A. Merkle and N. Lehnert, Structural and spectroscopic characterization of mononuclear copper(I) nitrosyl complexes: end-on versus side-on coordination of NO to copper(I), J. Am. Chem. Soc., 2008, 130, 1205-1213.
67 A. C. Merkle and N. Lehnert, The side-on copper(I) nitrosyl geometry in copper nitrite reductase is due to steric interactions with isoleucine-257, Inorg. Chem., 2009, 48, 11504-11506.

68 L. M. Murphy, F. E. Dodd, F. K. Yousafzai, R. R. Eady and S. S. Hasnain, Electron donation between copper containing nitrite reductases and cupredoxins: the nature of proteinprotein interaction in complex formation, J. Mol. Biol., 2002, 315, 859-871.

69 M. Kukimoto, M. Nishiyama, M. E. Murphy, S. Turley, E. T. Adman, S. Horinouchi and T. Beppu, X-ray structure and site-directed mutagenesis of a nitrite reductase from Alcaligenes faecalis S-6: roles of two copper atoms in nitrite reduction, Biochemistry, 1994, 33, 5246-5252.

70 M. Kukimoto, M. Nishiyama, T. Ohnuki, S. Turley, E. T. Adman, S. Horinouchi and T. Beppu, Identification of interaction site of pseudoazurin with its redox partner, copper-containing nitrite reductase from Alcaligenes faecalis S-6, Protein Eng., 1995, 8, 153-158.

71 M. D. Vlasie, R. Fernandez-Busnadiego, M. Prudencio and M. Ubbink, Conformation of pseudoazurin in the $152 \mathrm{kDa}$ electron transfer complex with nitrite reductase determined by paramagnetic NMR, J. Mol. Biol., 2008, 375, 1405-1415.

72 M. Nojiri, in Metalloenzymes in Denitrification: Applications and Environmental Impacts, ed. I. Moura, J. Moura, S. Pauleta and L. Maia, The Royal Society of Chemistry, 2017, ch. 5, pp. 91-113, DOI: 10.1039/9781782623762-00091.

73 S. Suzuki, T. Kohzuma, S. Shidara, K. Okhki and T. Aida, Novel spectroscopic aspects of type 1 copper in Hyphomicrobium nitrite reductase, Inorg. Chim. Acta, 1993, 208, 107-109.

74 M. Nojiri, Y. Xie, T. Inoue, T. Yamamoto, H. Matsumura, K. Kataoka, W. Deligeer, K. Yamaguchi, Y. Kai and S. Suzuki, Structure and function of a hexameric copper-containing nitrite reductase, Proc. Natl. Acad. Sci. U. S. A., 2007, 104, 4315-4320.

75 S. V. Antonyuk, C. Han, R. R. Eady and S. S. Hasnain, Structures of protein-protein complexes involved in electron transfer, Nature, 2013, 496, 123-126.

76 I. Schlichting, J. Berendzen, K. Chu, A. M. Stock, S. A. Maves, D. E. Benson, R. M. Sweet, D. Ringe, G. A. Petsko and S. G. Sligar, The catalytic pathway of cytochrome p450cam at atomic resolution, Science, 2000, 287, 1615-1622.

77 S. Nakano, M. Takahashi, A. Sakamoto, H. Morikawa and K. Katayanagi, The reductive reaction mechanism of tobacco nitrite reductase derived from a combination of crystal structures and ultraviolet-visible microspectroscopy, Proteins, 2012, 80, 2035-2045.

78 T. Beitlich, K. Kuhnel, C. Schulze-Briese, R. L. Shoeman and I. Schlichting, Cryoradiolytic reduction of crystalline heme proteins: analysis by UV-Vis spectroscopy and X-ray crystallography, J. Synchrotron Radiat., 2007, 14, 11-23.

79 E. F. Garman and M. Weik, X-ray radiation damage to biological macromolecules: further insights, J. Synchrotron Radiat., 2017, 24, 1-6.

80 J. McGeehan, R. B. Ravelli, J. W. Murray, R. L. Owen, F. Cipriani, S. McSweeney, M. Weik and E. F. Garman, 
Colouring cryo-cooled crystals: online microspectrophotometry, J. Synchrotron Radiat., 2009, 16, 163-172.

81 D. von Stetten, T. Giraud, P. Carpentier, F. Sever, M. Terrien, F. Dobias, D. H. Juers, D. Flot, C. Mueller-Dieckmann, G. A. Leonard, D. de Sanctis and A. Royant, In crystallo optical spectroscopy (icOS) as a complementary tool on the macromolecular crystallography beamlines of the ESRF, Acta Crystallogr., Sect. D: Biol. Crystallogr., 2015, 71, 15-26.

82 R. L. Owen, B. A. Yorke, J. A. Gowdy and A. R. Pearson, Revealing low-dose radiation damage using single-crystal spectroscopy, J. Synchrotron Radiat., 2011, 18, 367-373.

83 D. Kekilli, F. S. Dworkowski, G. Pompidor, M. R. Fuchs, C. R. Andrew, S. Antonyuk, R. W. Strange, R. R. Eady, S. S. Hasnain and M. A. Hough, Fingerprinting redox and ligand states in haemprotein crystal structures using resonance Raman spectroscopy, Acta Crystallogr., Sect. D: Biol. Crystallogr., 2014, 70, 1289-1296.

84 I. Polsinelli, M. Savko, C. Rouanet-Mehouas, L. Ciccone, S. Nencetti, E. Orlandini, E. A. Stura and W. Shepard, Comparison of helical scan and standard rotation methods in single-crystal X-ray data collection strategies, J. Synchrotron Radiat., 2017, 24, 42-52.

85 I. Schlichting, Serial femtosecond crystallography: the first five years, IUCrJ, 2015, 2, 246-255.

86 M. P. Blakeley, S. S. Hasnain and S. V. Antonyuk, Sub-atomic resolution X-ray crystallography and neutron crystallography: promise, challenges and potential, IUCrJ, 2015, 2, 464-474. 